\title{
NOTAS
}

\section{La Unión Europea ante la inmigración}

\section{Eduardo Moyano Estrada'}

\begin{abstract}
Revista de Fomento Social acoge la colaboración sobre una cuestión de evidente actualidad del miembro del Consejo de Redacción, profesor Moyano Estrada, a quien agradecemos su autorización para publicar una contribución oral, previa a este texto revisado por el autor. En la próxima entrega aparecerá una nota de la redacción de la revista sobre este mismo tema y la cuestión urgente de los refugiados en Europa.
\end{abstract}

Resumen: La actualidad mediática y política ha vuelto a poder en el centro del debate público la cuestión de las migraciones y, más concreta y urgentemente, la de los refugiados que acuden a Europa y las políticas públicas de los Estados europeos ante estos hechos. La nota parte de algunas constataciones previas: la permanencia de la cuestión migratoria en la agenda política, así como el análisis de algunos factores que, no por ser menos evidentes, dejan de ser esenciales para comprender la cuestión, además del trasfondo del declive demográfico europeo. En la segunda parte, el autor esboza algunas propuestas de actuación política, antes de concluir que éste es un tema que está y seguirá estando presente en la agenda política, lo que refuerza la condición plural y la diversidad en la riqueza de la integración europea. La cuestión migratoria, con toda su complejidad, seguirá presente en los próximos años en Europa, especialmente para la Unión Europea: las respuestas a esa cuestión debemos buscarlas en el propio patrimonio ético-jurídico-político europeo.

Palabras clave: Acciones de origen (cooperación y desarrollo), AcNUR, agenda política, declive demográfico, migraciones, política común europea de asilo e inmigración, refugiados, Unión Europea, valores europeos.

' Profesor de investigación, sociólogo. IESA-CSIC. Córdoba. emoyano@iesa.csic.es 
Fecha de recepción: I de septiembre de 2015.

Fecha de admisión definitiva: 14 de octubre de 2015.

\section{The European Union and immigration}

Abstract: Today the media and political power has returned to the center of the issue of migration and public debate, more concrete and urgent, refugees who come to Europe and public policies of the European States to these facts. The note is based on some preliminary findings: the permanence of the immigration issue on the political agenda, as well as the analysis of some factors which are not to be less obvious, less essential for understanding the issue, as well as the background of the European demographic decline. In the second part, the author outlines some proposals for policy action, before concluding that this is a topic that is and will continue to be present in the political agenda, which reinforces the plural condition and diversity in the richness of European integration. The immigration issue, with all its complexity, will continue in the coming years in Europe, especially for the European Union: the answers to that question must seek them in own ethical-polithic european heritage.

Key-words: Shares in origin (cooperation and development), UNHCR, political agenda, demographic decline, migration, common European policy of asylum and immigration, refugees, European Union, European values.

\section{L'Union européenne et l'immigration}

Résumé: Aujourd'huil'acualité médiatique et politique a repris le pouvoir dans le centre du débat public la question des migrations et, plus concrète et urgente, celle des réfugiés qui viennent en Europe, ainsi que les politiques publiques des États européens face à ces faits. La note se base sur quelques conclusions préliminaires: la permanence de la question de l'immigration sur l'agenda politique, ainsi que l'analyse de certains facteurs qui ne doivent ne pas être moins évidentes et moins essentielles pour comprendre la question, par exemple l'arrière-plan du déclin démographique européen. Dans la deuxième partie, l'auteur donne un aperçu des propositions d'action politique, avant de conclure qu'il s'agit d'un sujet qui est et continuera d'être présent dans l'agenda politique, ce qui renforce la condition plurielle, riche et diverse de l'intégration européenne. La question de l'immigration, avec toute sa complexité, se poursuivra dans les prochaines années en Europe, en particulier pour l'Union européenne: les réponses à cette question doivent partir de son propre patrimoine éthique-politique européen.

Mots clé: Actions d'origine (coopération et développement), HCR, l'agenda politique, déclin démographique, migration, politique européenne commune d'asile et l'immigration, réfugiés, Union européenne, valeurs européennes 
Sobrecoge la imagen de cadáveres flotando en el Mediterráneo después de su frustrada travesía al paraíso europeo. Igual de sobrecogedoras son las imágenes de cientos de inmigrantes en lanchas a la deriva que, afortunados ellos, han podido ser rescatados por los guardacostas italianos o españoles o por los barcos de Médicos sin Fronteras, y llevados a los centros de acogida de Lampedusa o de alguna de las islas griegas. Conmueven los sucesivos intentos de inmigrantes subsaharianos por saltar la valla de concertinas de Melilla, o la imagen de los que, hacinados en tiendas de campaña en las playas de Calais, esperan días y noches intentando pasar al Reino Unido a través del eurotúnel. Sobrecogen también las escenas de los refugiados que se aglomeran en las fronteras de Macedonia, Croacia o Hungría y que nos recuerdan tiempos que ya creíamos olvidados en Europa. Pero si todo eso conmueve, aún más sobrecoge pensar en el larguísimo y complicado itinerario que hacen los inmigrantes desde sus lugares de origen (Siria, Libia, Iraq, Afganistán, Eritrea, Somalia, Nigeria, Chad,...) para llegar a las fronteras europeas tras recorrer miles de kilómetros.

Sentimientos aparte, la cuestión migratoria es un tema de gran complejidad para el que no hay fácil solución. Sin embargo, aunque sea un asunto complejo, la ciudadanía europea debe interesarse por él, pensar en cuál debería ser nuestra actitud como ciudadanos, no mirando nunca a otro lado como si el problema no existiera. El objetivo de este breve artículo es compartir algunas reflexiones sobre la cuestión migratoria y exponer algunas propuestas de actuación. Mi propósito es poner algo de racionalidad en un debate que, en ocasiones, adquiere tintes demagógicos, y salir de la impotencia que solemos sentir ante un drama de estas proporciones.

\section{I.Algunas reflexiones}

1) El tema migratorio está aquí para quedarse. Es un asunto estructural, aunque haya determinados factores coyunturales que lo activen en determinadas épocas (guerras regionales, malas condiciones climáticas, desastres ecológicos, hambrunas, altas expectativas de empleo en los países europeos, ...). Ya sea en busca de mejores oportunidades laborales (inmigrantes económicos), ya sea huyendo de zonas de guerra (refugiados políticos) (en las que algunos gobiernos occidentales no están exentos de responsabilidad, como es el caso de Siria, Iraq o Libia), lo cierto es que el tema migratorio es un hecho consustancial con nuestro tiempo. Además, aunque jurídicamente esté clara la diferencia entre "refugiados" (que tienen derecho a solicitar asilo en el país al que lleguen) e "inmigrantes" (que sólo pueden solicitar permiso de residencia, mucho más restrictivo que el derecho de asilo), la realidad es que, socialmente, cada vez es más difícil discernir entre esas 
dos categorías de emigrados, porque qué diferencia hay entre huir del hambre y la pobreza extrema, y escapar de la guerra o la represión política.

El afán por encontrar una vida mejor (sea cual fuere su motivación) es imparable por muchas vallas o muros de contención que se pongan en nuestras fronteras. Es un afán favorecido, además, en tiempos de globalización, por los rápidos flujos de información que alcanzan los lugares más recónditos del planeta, por la facilidad con que se produce el tránsito entre países o por la movilidad de las personas en un mundo tan interconectado como el nuestro. Mientras haya grandes desigualdades económicas entre países; mientras haya zonas de inestabilidad política y de conflictos bélicos cerca de las fronteras europeas; mientras sea fácil moverse de unos lugares a otros, y mientras la información fluya a ritmo de vértigo en las redes sociales, la inmigración estará presente entre nosotros y tendremos que acostumbrarnos a convivir con ella.

2) La mayor parte de los inmigrantes que han llegado a Europa en los últimos años lo han hecho por los puertos, aeropuertos o estaciones del ferrocarril, con pasaportes o visados de turista o de estudiante, o bien con un contrato de trabajo. Otros, como la oleada migratoria de los últimos meses, huyen a la desesperada de zonas en guerra (Siria, Iraq, Afganistán,...), proceden de estados fallidos (Libia, Eritrea, ...) o vienen de situaciones de pobreza extrema (países subsaharianos), donde, al no expedirse ni pasaportes ni documentos de identidad, utilizan el tráfico ilegal de personas para llegar a Europa. Sea como fuere la vía utilizada, y el modo legal o ilegal de entrada, lo cierto es que, una vez dentro, intentarán quedarse en los países europeos, moviéndose de unos lugares a otros hasta encontrar la mejor opción que les permita desarrollar sus proyectos personales y familiares y satisfacer sus expectativas de una vida mejor.

A pesar de lo impactante de las cifras sobre el número de inmigrantes que arriban a las islas griegas o a las costas italianas o españolas (casi medio millón en lo que va de año, según informa la agencia europea Frontex), o de las cifras referidas a los refugiados que se agolpan en las fronteras orientales de la UE, hay que tener en cuenta que es sólo una pequeña parte del movimiento migratorio. Para darle al tema su verdadera magnitud, hay que recordar, además, que, en lo que se refiere al tema de los refugiados políticos, y según datos de Alto Comisionado de las Naciones Unidas para los Refugiados (ACNUR), más del $80 \%$ son acogidos por los países limítrofes a las zonas de conflicto (Turquía, Jordania, Líbano,...). Además, hay que tener en cuenta que, para estos países, la llegada de miles de refugiados representa un auténtico problema de emergencia nacional, al que le dan respuesta como pueden en una muestra de solidaridad que ya quisiéramos en la Europa de la abundancia. Así, mientras que, en la UE, la cantidad de inmigrantes 
y refugiados que han llegado a nuestras fronteras sólo alcanza el 0,1\% de la población europea, en Líbano, por ejemplo, representan ya un 30\% de su población.

Para hacerse una real composición de lugar sobre el problema, hay que tener en cuenta también que muchos de los refugiados e inmigrantes que llegan a Europa son personas con formación y recursos suficientes como para poder abrirse paso en nuestros países si encuentran oportunidades para hacerlo. Les avala, además, el coraje, vitalidad y espíritu de superación que han mostrado para hacer frente a las grandes dificultades que han debido superar hasta llegar a suelo europeo. No son tan estúpidos como para quedarse en países donde no hay posibilidades de encontrar empleo o de abrir algún negocio, por lo que, una vez cruzada la frontera de la UE, buscarán el país más idóneo para sus proyectos de vida, disponiendo para ello de redes de contactos con familiares, amigos o compatriotas. Por eso, la decisión de la Comisión Europea de asignar cuotas de acogida a todos los países de la UE, sólo puede verse como una solución de urgencia para aliviar la presión que sufren los países más afectados por su situación fronteriza, ya que no es un problema de estos países, sino un problema europeo que requiere una solución europea. Las cuotas, además de que son ineficaces a medio plazo, no pueden sustituir lo que debe ser en el futuro una política común en materia de asilo e inmigración.

3) En la llegada a Europa y en el tránsito ilegal de inmigrantes por los países europeos, intervienen mafias especializadas, que, según datos de Naciones Unidas, gestionan hoy uno de los negocios más rentables, superando incluso el del tráfico de drogas (se estima entre 1.000 y 3.000 euros lo que tiene que pagar un inmigrante a las mafias para facilitar su entrada en Europa). Esas mafias no sólo están en los países de origen o asentados en las costas del Mediterráneo desde donde parten los inmigrantes en travesías de alto riesgo, sino que también están en los propios países europeos. Si no fuera así, sería difícil transitar de manera ilegal desde los países periféricos del sur europeo a los más ricos del norte, o desde los países del este a los del centro de la UE. La reciente noticia del camión encontrado en las carreteras austriacas con setenta cadáveres de inmigrantes ilegales en su vagón, es estremecedor, y prueba de que las mafias que trafican con personas también están presentes en territorio europeo.

4) No hay en la UE una política verdaderamente común sobre migración. Lo que hay son acuerdos de cooperación entre gobiernos nacionales para afrontar el problema migratorio, una cooperación que se intensifica en determinadas coyunturas, cuando ese problema se desborda y adquiere resonancia internacional, como está ocurriendo ahora, o cuando se produce algún acontecimiento luctuoso. La cooperación entre los gobiernos nacionales es compleja, y más en una situación de crisis económica como la actual, ya que cada país procura conciliar, de un 
lado, el compromiso a que le obliga el hecho de formar parte de la UE, y de otro, la defensa de los intereses nacionales y la capacidad real para hacer frente a ese problema en función de su situación económica y su posición geográfica (hay países, como Italia, Grecia o España, pero también Hungría o Croacia, que son más vulnerables que otros a la inmigración ilegal, aunque, como estamos viendo, cualquier país europeo puede verse afectado de manera directa o indirecta).

A la ya compleja cooperación intergubernamental en la UE, habría que añadir la complejidad de un tema como éste, dado que no todos los países europeos han firmado el tratado de Schengen sobre libre circulación de personas, y dado también que cada país tiene su propia legislación sobre asilo y extranjería. Por ello, los avances en la gestión del problema migratorio son lentos. No obstante, se han dado pasos importantes, aunque insuficientes, como el Convenio de Dublín (2003) (hoy bastante cuestionado, debiendo ser reformado para actualizarlo a la realidad actual del problema migratorio) o el Pacto Europeo sobre Migración y Asilo (PEMA) (2008), que van en la dirección de una política común, pero que aún está lejos de poderse llamar así. Otro paso importante ha sido el acuerdo del Consejo de Ministros de Interior de la UE del pasado mes de septiembre (22/09/2015), en el que se establecieron, no sin tensas negociaciones, cuotas por países para acoger a los 150.000 inmigrantes internados en los centros de Italia y Grecia, pero que probablemente serán pronto desbordadas ante la llegada de nuevos inmigrantes (ACNUR prevé que cruzarán el Mediterráneo en el próximo año cerca de un millón personas con destino a algún país europeo). El reciente acuerdo de la Comisión Europea de librar 2.400 millones de euros de los fondos AMIF (migración y asilo) e ISF (emergencia) para atender las necesidades de acogida es una decisión significativa, pero a todas luces insuficiente, que tendrá que ampliarse. Lo mismo ocurre con los 1.000 millones de euros destinados a mejorar las condiciones de los campos de refugiados de los países limítrofes a Siria, que son de donde proceden la mayor parte de los que llegan a Europa.

La suspensión temporal del espacio Schengen por algunos países (como Alemania, Austria, Holanda,...), la reunión extraordinaria del Consejo de Jefes de Estado y de Gobierno de la UE celebrada el pasado 23 de septiembre, o la intervención conjunta en el Parlamento Europeo el pasado 8 de octubre del presidente francés Hollande y la canciller alemana Merkel, son indicativos de la gravedad del problema. Este problema está poniendo en riesgo la cohesión entre los Estados europeos, y generando graves tensiones entre ellos: por ejemplo, con el gobierno ultranacionalista de Victor Orban en Hungría (que ha vallado su frontera tanto externa, como interna) o con el del socialdemócrata eslovaco Robert Fico (que ha presentado un recurso ante el Tribunal de Justicia de la UE por la decisión de crear cuotas obligatorias de 
acogida en lo que considera una extralimitación de las facultades de la Comisión Europea en temas que aún no forman parte de la política común).

Sin embargo, a pesar de las dificultades de poner en marcha una política europea de migración, y de las tensiones políticas antes comentadas, algunos gobiernos de los Estados miembros de la UE (especialmente, los de su frontera meridional, como Grecia, Italia o España) vienen realizando desde hace años grandes esfuerzos para gestionar el problema que les supone la llegada masiva a sus territorios de inmigrantes y refugiados políticos.

Tomando como referencia el caso de España, existe una red de centros de acogida que han venido funcionando razonablemente bien, pero que hoy se encuentran al límite de sus capacidades. Por ejemplo, existen dos CETI (centros de estancia temporal de inmigrantes), uno en Ceuta y otro en Melilla (dependientes actualmente del Ministerio de Empleo, al estar en ese ministerio la DG de Política Migratoria), con capacidad de acogida de un millar de inmigrantes y dotados de personal especializado para atenderlos justo en el momento de su llegada a nuestro país; en los CETI permanecen hasta un máximo de seis meses, aunque en la práctica ese periodo se prolonga de forma ilimitada. Existen también varios CAR (centros de acogida al refugiado) en diversas ciudades españolas, para aquellos inmigrantes que, esgrimiendo el estatuto de refugiado, solicitan asilo político y están pendientes de su resolución. Finalmente, hay nueve $\mathrm{CIE}$ (centros de internamiento de extranjeros) (dependientes del Ministerio del Interior y distribuidos por varias ciudades) donde son acogidos, durante un máximo de sesenta días, los inmigrantes que, una vez finalizada su estancia en los CETI, están a la espera de que se les resuelva sus expedientes de expulsión en aplicación de la ley de extranjería.

Estas tres clases de centros públicos de acogida, a los que cabría añadir la red de centros concertados, están bien equipados y disponen de dotaciones para prestar servicios de atención sanitaria y de formación a los inmigrantes, estableciéndose, además, convenios de colaboración con otras entidades de naturaleza privada, como Cruz Roja y diversas ONG especializadas en este área. La actividad de estos centros está sometida al control y vigilancia de las autoridades competentes, pero también de las propias ONG, siendo supervisados, además, por el Consejo de Europa para que las personas allí alojadas reciban un trato acorde con el respeto de los derechos humanos. Obviamente, dada la singularidad de los casos y la diversidad de las situaciones que se presentan en estos centros, no es extraño que en el día a día surjan tensiones entre las autoridades encargadas de su gestión y los refugiados e inmigrantes allí acogidos, dando pie a denuncias y protestas de las ONG y demás organizaciones de defensa de los derechos humanos. 
5) La UE necesita de la inmigración para resolver su declive demográfico. Es un hecho que gran parte de los países de la UE (sobre todo, los que tienen economías más desarrolladas) experimenta un descenso demográfico de tal magnitud, que pone en peligro la sostenibilidad de sus sistemas de bienestar. Estudios de prospectiva de la OCDE señalan que entre 2013 y 2020 la población en edad de trabajar se reducirá en 7,5 millones de personas en la UE. La Fundación Bertelsmann calcula que la economía alemana necesitará incorporar cada año medio millón neto de inmigrantes si quiere mantener estable el número de trabajadores que cotizan a la seguridad social. Esas reflexiones, con algunas variaciones, valen para otros países, como Francia, Reino Unido o el Benelux. Por eso, como señalaba Joschka Fischer (quien fuera ministro alemán de Asuntos Exteriores) en un artículo publicado el pasado 25 de agosto en el diario El País, no deberíamos ver a los refugiados e inmigrantes como una amenaza, sino como una oportunidad, aunque sólo sea por la necesidad que tiene la UE de aumentar su población activa.

Esa forma de ver el tema migratorio debe llevarnos a los europeos a aceptar el cambio social que ello implica, admitiendo que no se puede tener prosperidad económica y alto nivel de bienestar (en forma de pensiones y prestaciones sociales) sin incorporar al mercado de trabajo la población activa que los países europeos necesitan para financiar su costoso sistema de seguridad social y que no pueden ofrecer por sí solos debido al declive demográfico de su población. La incorporación de inmigrantes será necesaria (si no lo es ya en algunos países europeos), y eso significa asumir la complejidad de integrar a personas educadas en culturas diferentes de la europea y con creencias religiosas distintas del cristianismo.

Ello exige hacer mucha pedagogía en la ciudadanía para comprender que ya no tiene sentido enarbolar, como si fueran elementos esenciales de la UE, la bandera de una cultura y una identidad europeas que sólo existen en el imaginario colectivo de algunos grupos hipernacionalistas. Debemos admitir que la identidad europea no es homogénea, sino diversa, y para comprender eso basta pensar en las diferencias culturales de los países que hoy conforman la Unión. La UE ya es plural, y es precisamente en su diversidad cultural donde radica la fuerza y la riqueza del proyecto europeo, un proyecto cuya seña de identidad no está en la cultura, sino en el hecho de compartir valores comunes en torno a la democracia, la tolerancia y el respeto a los derechos humanos. La llegada de inmigrantes y refugiados aumentará, sin duda, la diversidad cultural de la UE, tal como viene ocurriendo en los EE. UU. desde hace un siglo, sin que eso haya sido un obstáculo para que la primera potencia económica del mundo, lo siga siendo. Lo que tenemos es que prepararnos para asimilar el fenómeno migratorio, ya que, como he señalado, ha venido para quedarse. 
Ante la magnitud y complejidad del problema, una UE basada en los valores de la libertad (de expresión y de circulación), la justicia, la solidaridad y el respeto de los derechos humanos, no puede ignorar el problema, a riesgo de desdibujar el proyecto europeo en favor de lógicas nacionales de corte populista y xenófobo. Muchas naciones europeas (entre ellas España) han sido países de emigración, y debemos retener en nuestra memoria colectiva lo que significa para un emigrante salir de su patria para buscar una nueva vida en un país extraño y desconocido. Nuestra memoria está asociada a la salida desesperada de cientos de miles de refugiados españoles en 1939 después de la Guerra Civil en dirección a Francia y México, y también a la imagen de los emigrantes que salieron en los años 60 a Alemania, Francia o Suiza.

Llegados a este punto, y dado que, en ocasiones, se convierte en lugar común de tertulias y conversaciones informales el tema de la contratación en origen, conviene señalar que sólo una minoría de los que hoy emigran lo hace con un contrato de trabajo. En la realidad actual de la emigración, los contratos en origen representan una ínfima parte de los flujos migratorios, limitándose por lo general al sector agrario y en regiones muy concretas donde hay cierta tradición de contratar en el país de origen (por ejemplo, en la recogida de la fresa en Huelva o de la uva en Francia). En su inmensa mayoría, los flujos migratorios de hoy son flujos mixtos, sin ningún tipo de control ni previsión en origen.

\section{Algunas propuestas de actuación}

Sin caer en actitudes cándidas e ingenuas, la UE debe seguir actuando ante este drama humano con firmeza, pero sin abandonar los valores que la identifican como una sociedad civilizada, ni tampoco incumplir el derecho y los tratados internacionales sobre asilo y circulación de personas. Su actuación debe centrarse, al menos, en cinco grandes ejes, en torno a los cuales ya se están desarrollando algunas de las acciones antes comentadas, pero en las que se tiene que avanzar y profundizar aún más.

i) Salvar vidas. La UE no puede permitir que el Mediterráneo se convierta en un cementerio, y para eso ha de reforzar los servicios de vigilancia costera para acudir al salvamento de cualquier barcaza a la deriva cargada de inmigrantes. $\mathrm{Ni}$ un muerto más en nuestros mares. El derecho internacional marítimo obliga a atender a cualquier persona que esté en peligro de naufragio en alta mar. Es un deber moral y una obligación jurídica. 
ii) Actuar contra las mafias. Se precisa una acción coordinada con los gobiernos de los países de origen o tránsito para desmantelar las mafias que actúan allí, y emprender actuaciones conjuntas de las policías europeas para atacar el tráfico ilegal de personas en el territorio de la UE. No es tarea fácil, pero tampoco lo es luchar contra el narcotráfico o contra el terrorismo yihadista y hay dentro de los servicios de policía departamentos especializados en esas tareas.

iii) Atender al que llegue. No es cuestión de abrir de par en par las fronteras como algunas organizaciones o individuos bien intencionados reclaman, ni de relajar los controles fronterizos a que todo Estado tiene derecho. Los sistemas democráticos se basan en el respeto de las leyes, y las que existen sobre extranjería y asilo hay que cumplirlas, mientras no se modifiquen. Sin embargo, sólo en situaciones de emergencia, como las producidas en estos últimos meses con la llegada masiva de refugiados, estaría justificado por razones humanitarias que se abrieran de forma ordenada las fronteras europeas para darles acogida, como ya ocurrió en otras circunstancias históricas (la más reciente, durante la guerra de los Balcanes). Dicho esto, lo importante es que, una vez dentro, nuestro primer deber es atenderlos de manera digna. No son delincuentes los que llegan, sino personas que buscan una vida mejor. Llegar de manera ilegal no es un delito, al menos por ahora, ya que algunos países como Hungría están modificando su legislación penal para declarar delictivo ese comportamiento y castigarlo incluso con penas de prisión. Mientras tanto, nuestro primer deber es atenderlos en los centros dispuestos para esa finalidad, $y$, una vez atendidos como corresponde (lo que incluye atención sanitaria y escolar), aplicársele la legislación vigente en cada país, tramitando las solicitudes de asilo para todos aquellos que tengan derecho a presentarlas y aplicando las leyes de extranjería al resto. Aplicar la legislación vigente, también incluye, sin duda, la expulsión, pero ésta debe hacerse de acuerdo con la legalidad y con todas las garantías procesales. Nada de devoluciones en caliente ni de expulsiones a no se sabe dónde. Los que llegan no son paquetes de carne que se devuelven si no nos gustan, sino seres humanos con su dignidad como personas que huyen de la miseria o la guerra y a los que se les debe tratar con el respeto debido ofreciéndoles oportunidades para su integración. Si hace falta habilitar más centros de acogida o ampliar los ya existentes, la UE debe librar fondos suficientes para ello, tal como está ya haciendo, aunque todavía de forma poco acorde con la magnitud del problema. La ya citada asignación de cuotas obligatorias por países para dar acogida y atención a los miles de inmigrantes que están llegando a las puertas de la UE, es, como he señalado, una solución de urgencia para dar respuesta inmediata y solidaria a un problema que no es nacional, sino europeo. Pero la política de cuotas no resolverá el problema, ya que es un simple paliativo a lo que debería ser una real política común en materia de asilo e inmigración. 
iv) Avanzar en una política común europea de asilo e inmigración. La cooperación intergubernamental en asilo e inmigración, diseñada a finales de los años noventa y principios de este siglo XXI, y regulada por el Convenio de Dublín, se ha visto desbordada, por lo que dicho convenio tendrá que ser modificado. La actual crisis migratoria que afronta la UE debe ser aprovechada como una oportunidad para avanzar en una verdadera política común europea en este área, tanto unificando los criterios de concesión de asilo a los refugiados, como integrando en una legislación común las hoy desiguales y dispersas legislaciones nacionales de extranjería. No es bueno que haya países con legislaciones muy abiertas a la concesión de asilo o de permisos de residencia, junto a otros con legislaciones más restrictivas, ya que ello provocará, como está ocurriendo, que se concentren las solicitudes en los países donde sea más fácil conseguir la tan ansiada autorización. Sin embargo, esto no será fácil, dadas las reticencias de algunos gobiernos a perder soberanía en estas materias, pero no queda otra solución si no queremos que se despeñe el proyecto europeo que tanto esfuerzo está costando construir. Cabe destacar en este sentido el discurso de Angela Merkel (pronunciado ante el Bundestag en los primeros días de septiembre), quien, poniéndose a la altura de la gravedad del problema, advierte de que, si Europa no es capaz de abordar la cuestión migratoria como un tema europeo, el proyecto de la UE se vendrá abajo. No obstante, la situación en el momento de escribir este artículo, está lejos de solucionarse, y está creando, además, problemas políticos internos en países que se habían manifestado inicialmente bastante receptivos a la acogida de refugiados. Tal es el caso de la propia Alemania, donde se resquebraja el liderazgo de la canciller Merkel ante las críticas que recibe por parte de grupos de su propio partido democristiano (sobre todo, de su socio bávaro) y ante la presión de grupos ultranacionalistas como Pagida (ya extendidos en otros países europeos), que rechazan la llegada de refugiados e inmigrantes por considerarlos una amenaza a los valores occidentales.

v) Promover acciones de cooperación y desarrollo en los países de origen. Esto lleva su tiempo, y sus efectos sólo se perciben a medio y largo plazo. En algunos casos, las causas del problema migratorio proceden de la situación de pobreza que se vive en los países de origen. Es una situación que, además de estar vinculada a la ineficacia de gobiernos corruptos (muchos de ellos aliados de las potencias occidentales), está también ligada, en alguna medida, al sistema de extracción de materias primas que se viene haciendo en muchos países africanos por parte de grandes compañías transnacionales, y del que depende el modelo de desarrollo y consumo de nuestros países industrializados. Pero en otros casos, las causas están conectadas con situaciones bélicas que no tienen fácil solución (Siria, Iraq, Afganistán, Eritrea, Libia, Somalia, ...) y en las que, como sabemos, los gobiernos de ciertos países occidentales han tenido algún tipo de responsabilidad. 
Sin embargo, en aquellos países donde las causas estén claramente ligadas a la pobreza y el subdesarrollo, y donde haya estabilidad política, es necesario que los programas de cooperación y ayuda al desarrollo de la UE se concentren en ellos, aumentando su dotación hasta alcanzar al menos el 0,7\% del PIB europeo comprometido y nunca cumplido. Es hora de que la UE redefina su política de cooperación al desarrollo, estableciendo regiones prioritarias en el marco de los nuevos flujos migratorios. Asimismo, los programas de retorno voluntario de los inmigrantes que deciden regresar a sus países tras su experiencia en Europa, deberían ser una oportunidad para poner en marcha iniciativas empresariales en las regiones de donde proceden (en este sentido, cabe citar el programa que lleva a cabo con esa finalidad la Organización Internacional de las Migraciones).

\section{Conclusiones}

El tema migratorio es muy complejo, y adquiere hoy una dimensión dramática. Sin embargo, es un tema sobre el que la ciudadanía europea debe interesarse, a pesar de sus lógicas preocupaciones por la actual crisis económica y por los altos índices de desempleo existentes. Pero es un tema que seguirá estando presente en la agenda política europea una vez superados los actuales problemas económicos, debido a que, como he señalado, necesitaremos de la inmigración para afrontar las necesidades laborales de una UE cada vez más envejecida, tal como lo corroboran los últimos informes de prospectiva en materia de evolución demográfica.

Como ciudadanos europeos, debemos informarnos lo mejor posible sobre este tema para no caer en la demagogia de las soluciones fáciles. La diversidad cultural de la UE es algo consustancial al propio proyecto de construcción europea, porque es plural el sustrato sobre el que se ha edificado. Con o sin llegada de inmigrantes y refugiados, la realidad europea es diversa y plural. La acogida de los que llegan con otras culturas y creencias religiosas incrementará, sin duda, esa pluralidad, lo que nos obligará a hacer un esfuerzo mayor en un doble sentido.

En el terreno educativo, preparando a los ciudadanos europeos a convivir con la creciente diversidad cultural y religiosa, e integrando a los que llegan en los valores democráticos, que son la única y verdadera seña de identidad la UE. En el terreno político, incorporando la templanza en los discursos políticos, mostrando el lado positivo que tiene para el mantenimiento de nuestro sistema de bienestar la llegada de población inmigrante, aumentando los fondos para las políticas de acogida, y redefiniendo las políticas de cooperación internacional de la UE. 